\title{
Natural and Accelerated Bioremediation Research (NABIR) Field Research Center (FRC), Oak Ridge Tennessee ERKP329
}

Oak Ridge National Laboratory: David Watson (FRC Manager), Dr. Philip Jardine (FRC Science Advisor), Dr. Baohua Gu, (FRC Humics), Dr Jack Parker (Modeling), Craig Brandt (Database), Susan Holladay (Website), Dr. Amy Wolfe (Communications), Mary Anna Bogle (Health and Safety), and Kenneth Lowe and Kirk Hyder (Drilling, and Sample Collection, Analysis, and Shipping)

Research Objective: Advancing scientific understanding of the transportation, fate, and remediation of subsurface contamination sources and plumes - The Field Research Center (FRC) in Oak Ridge (Fig. 1), Tennessee supports the U.S. Department of Energy's (DOE's) Environmental Remediation Sciences Program (ERSP) goal of understanding the complex physical, chemical, and biological properties of contaminated sites for new solutions to environmental remediation and long-term stewardship. In particular, the FRC provides the opportunity for researchers to conduct studies that promote the understanding of the processes that influence the transport and fate of subsurface contaminants, the effectiveness and long-term consequences of existing remediation options, and the development of improved remediation strategies. It offers a series of contaminated sites around the former S-3 Waste Disposal Ponds and uncontaminated sites in which investigators and students conduct field research or collect samples for laboratory analysis. FRC research also spurs the development of new and improved characterization and monitoring tools. Site specific knowledge gained from research conducted at the FRC also provides the DOE-Oak Ridge Office of Environmental Management (EM) the critical scientific knowledge needed to make cleanup decisions for the S-3 Ponds and other sites on the Oak Ridge Reservation (ORR).

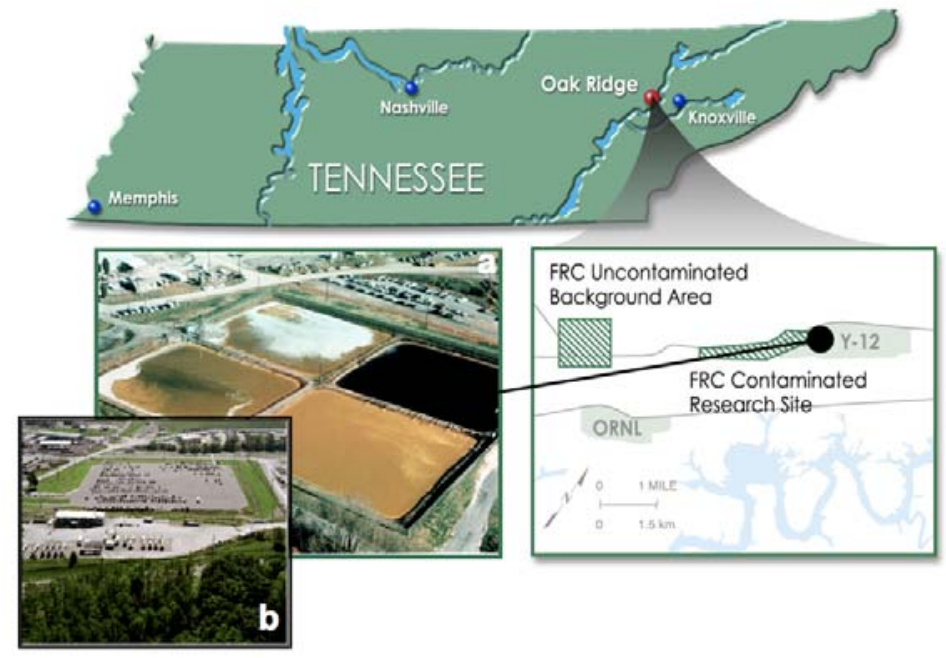

Fig. 1. Location of Oak Ridge Field Research Center; a) former S-3 Ponds during neutralization and denitrification just prior to closure in 1988; b) S-3 Ponds closed with a multilayer cap and paved at present.

The watershed-wide problems created by disposal are the subject of FRC research - No other field research facility investigates the subsurface fate and transport of contaminants on such a large scale using a real-world, contaminated site. Site characterization activities at the FRC have determined that wastes travel through two main pathways in the subsurface (Fig. 2). Each pathway has different geological, hydrological, and microbial characteristics. Wastes discharge 
to Bear Creek and the Maynardville Limestone, notable for its karst characteristics, and then migrate further down the watershed. The shale saprolite is the main pathway for nitrate and technetium and the gravel fill is the main pathway for uranium migration to Bear Creek. Our investigations show that uranium concentrations are highest where $\mathrm{pH}$ is low (pink in Fig. 2), but, that uranium is more mobile in the gravel where $\mathrm{pH}$ is high.
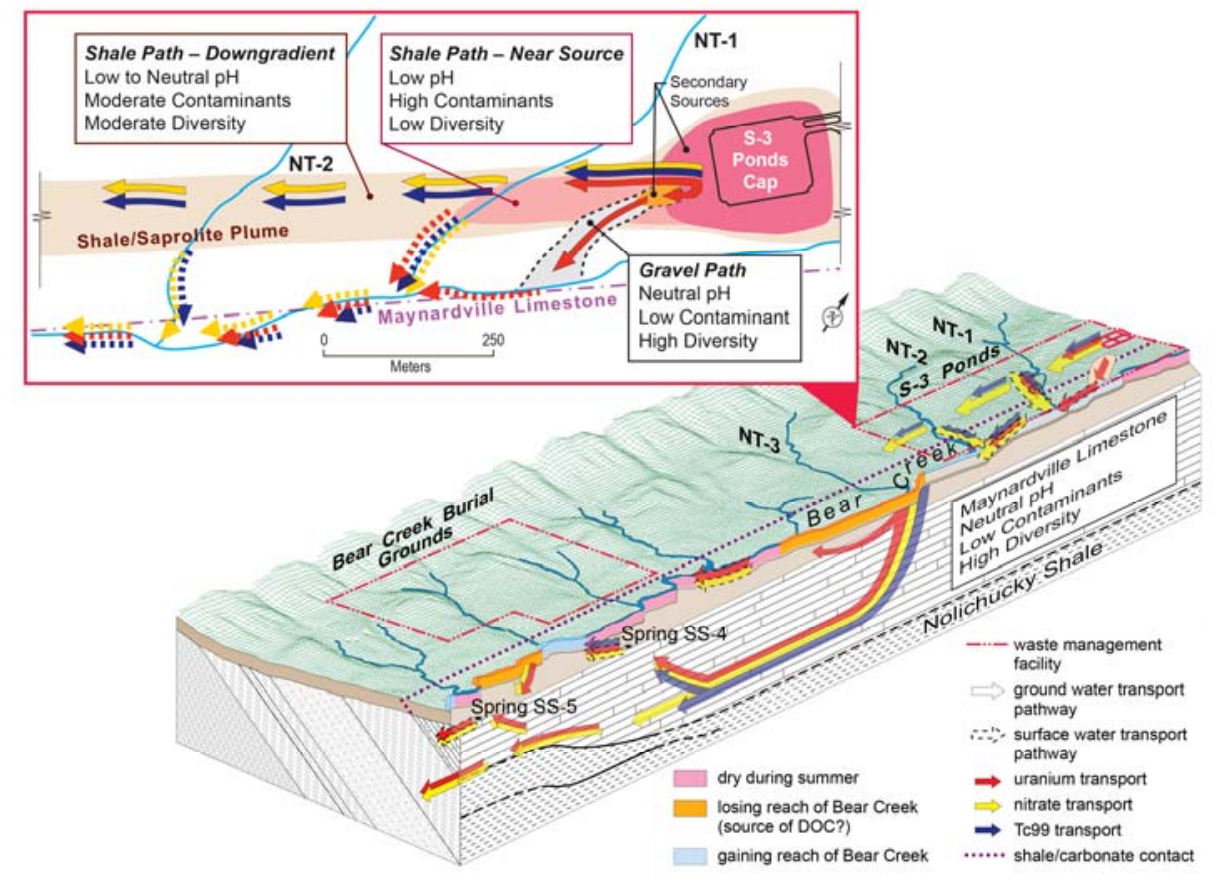

Fig. 2. Schematic diagram depicting major contaminant source zones and pathways in the watershed that encompasses the FRC and the impact of contaminant levels on microbial diversity

Research Progress and Implications: This report is for year six of a six-year project. Since April 2000 the FRC has conducted and/or assisted in a wide range of NABIR and ERSP activities including:

1. Supporting multi-disciplinary in situ accelerated bioremediation research projects

a) In-situ uranium reduction experiments using push-pull techniques (Lead - Oregon State University)

b) Field-scale bioreduction of uranium (Lead - Stanford University)

c) In situ immobilization of uranium in structured porous media via biomineralization at the fracture/matrix interface (Lead - PNNL)

2. Providing subsurface samples

a) Over 25,000 groundwater and core samples shipped to over 150 researchers at over 50 National Laboratories and Universities across the US and overseas

b) Humic material extracted and concentrated from FRC soils has been characterized and provided to PIs to use in their research

3. Conducting site characterization to support research projects and improve the site conceptual model

a) Drilling (e.g., Sonic, Holegator and Geoprobe) - Over 6,000 feet of drilling has been conducted to install over 120 new wells and over 120 coreholes

b) Geophysics, tracer, and hydraulic testing 
c) Sample analyses (e.g., ICP/MS, KPA, and IC) - Over 25,000 new analytical data records have been added to the FRC database

d) Mineralogical analyses (e.g., XRD, and SEM/EDX/BSE)

4. Supporting evaluation of new characterization and monitoring methods

a) Deployment of coupons (bug traps) for rapid assessment of in situ microbial activity (University of Tennessee, ORNL, INEEL, and others)

b) Development of microarray technology for assessment of community dynamics

c) Sequencing of at least one ORFRC subsurface model microorganism (Geobacter strain FRC-32) as well as completing sequencing of a metagenome from highly contaminated, acidic groundwater of the ORFRC at DOE's Joint Genome Institute (ORNL and LBNL)

d) Development of a highly annotated database of over 2600 gene sequences acquired from FRC samples (Florida State University)

e) Field-portable immunoassay instruments and reagents to measure chelators and mobile forms of uranium (Tulane University)

f) Characterization of the subsurface with surface and cross-well geophysics (ORNL and LBNL)

g) In situ uranium assay with downhole NaI detector (ORNL)

h) Sampling and analytical methods to quantify fixed gases present including $\mathrm{H}_{2}, \mathrm{O}_{2}$, $\mathrm{N}_{2}, \mathrm{~N}_{2} \mathrm{O}, \mathrm{CO}_{2}, \mathrm{CO}, \mathrm{CH}_{4}, \mathrm{He}$, and $\mathrm{Ne}(\mathrm{ORNL})$

i) Use of Permeable Environmental Leaching Capsules (PELCAPs) in combination with a handheld XRF to conduct in situ contaminant loading and leaching experiments (ORNL)

5. Development and calibration of an FRC site-wide numerical groundwater flow and transport model for use by the FRC and PIs

Major Discoveries - Research conducted by the FRC and scientists using the FRC has focused on determining if interventions can produce in situ bioreduction and immobilization of subsurface metal and radionuclide contamination. Listed below are results from these studies.

Radionuclide contaminants in groundwater reduced to below drinking water standards

1. Demonstrated at several locations that microbes found in the subsurface can transform uranium and technetium into chemical forms that are less mobile, and less toxic, in groundwater (Fig. 3)

2. Uranium and technetium reduction in field plots was maintained under anaerobic conditions for approximately 2 years

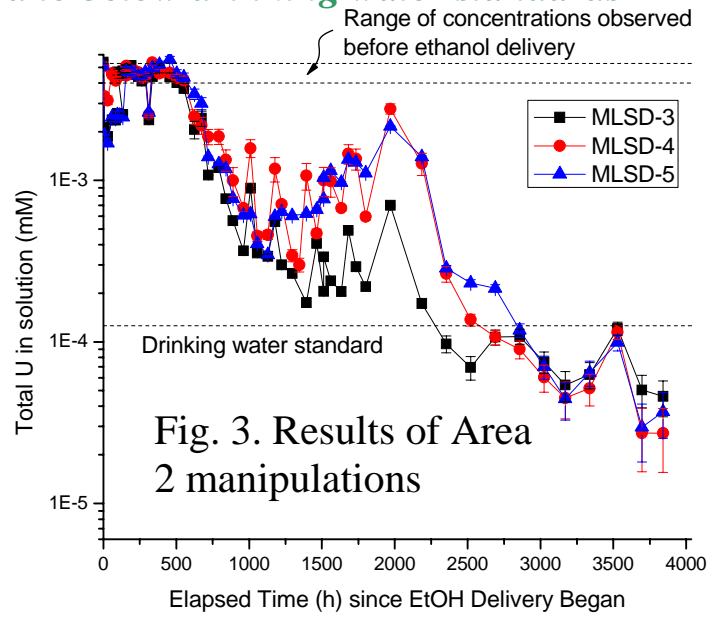


3. Dissolved oxygen and/or nitrate intrusion can reoxidize and remobilize bioreduced U(IV)

Several factors influence the mobilization or immobilization of subsurface contaminants

1. Documented that introducing naturally occurring humic substances (organic matter found in soil) can accelerate the chemical reduction and immobilization of uranium

2. Found that co-contaminants in the subsurface (e.g., nitrate) and elevated concentrations of other chemicals (e.g., calcium) can

a. inhibit the chemical reduction process

b. reoxidize uranium, making it more mobile

3. Identified the toxicity effects of $\mathrm{Ni}$ and other metals on microorganisms relevant to in situ metal bioremediation

Detailed understanding of complex subsurface environment was found to be important

1. Microbial populations and diversity are strongly influenced by $\mathrm{pH}$ and levels of contamination (Fig. 4)

2. Discovered that contaminants from secondary sources play an important role in FRC contaminant fate and transport (Fig. 5)

3. Described the impacts of disturbance-e.g., gravel fill material—on subsurface contaminant transport

4. High dissolved hydrogen concentrations in groundwater ( $>14 \%$ ppm-v) were discovered near the S-3 Ponds source area suggesting that there may be high metabolic activity beneath the S-3 Ponds cap

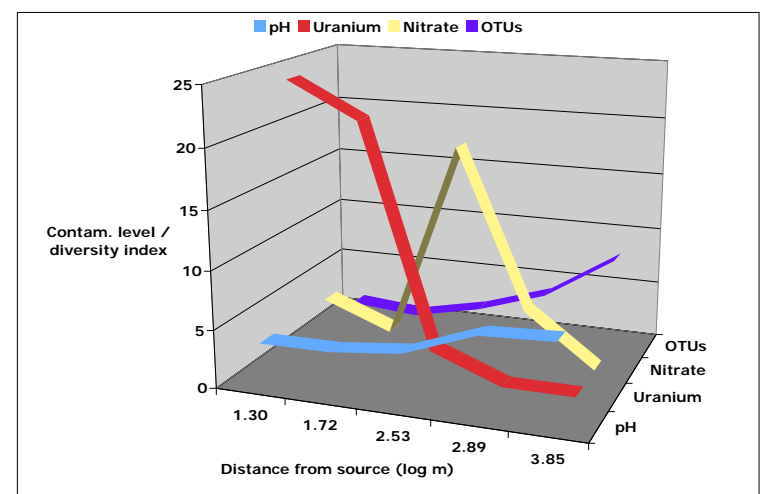

Fig. 4. Microbial diversity is shown to increase as contaminants decrease away from the source

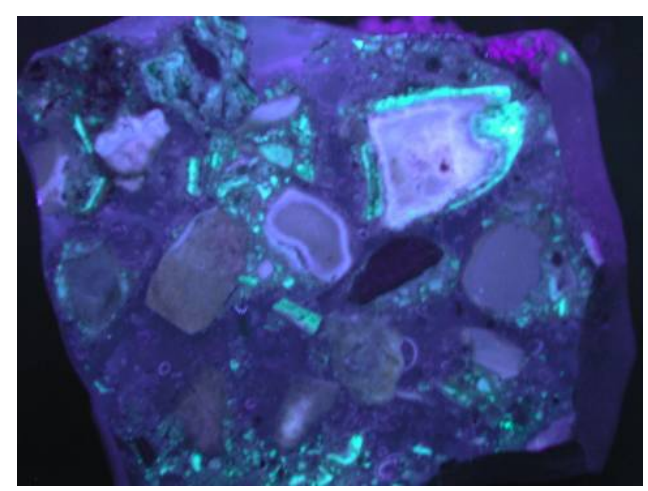

Fig. 5. U coatings on FRC gravel, shown fluorescing, act as secondary source

Planned Activities: Research at the FRC previously focused on active interventions to achieve accelerated microbially mediated bioreduction and immobilization of subsurface contaminants. However, this research clearly has shown the importance of understanding the ways in which multiple contaminants behave and move in the subsurface. It also is important to understand, monitor, and predict the long-term effectiveness of existing and new remediation technologies in real-world conditions at meaningful scales. The FRC lends itself to watershed-scale analyses. The FRC constitutes an excellent resource for research on persistent questions about the course and long-term effectiveness of attenuation and other extant remediation practices (e.g., capping, pumping-and-treating contaminants in groundwater, etc.). This research could help to track the movement of entire contaminant plumes in the subsurface over time, thereby providing new 
kinds of information that can help in remediation and monitoring decision making. For example, the ability to integrate data across the width of a plume over time provides information key to identifying important monitoring locations. Below are some of the many research topics associated with long-term stewardship that could be the subject of future field research at the FRC or laboratory research conducted with FRC samples.

Watershed issues and processes

1. Watershed responses to large-scale remediation

2. Surface water-groundwater-biology interactions

3. Plume sustainability from multiple - primary and secondary—sources

4. Mercury cycling in the environment and biological communities

$>$ New, potentially revolutionary remediation techniques and processes

1. Abiotic, biotic, mechanical methods

2. Enhancements to capping technologies

3. Identifying and cutting off migration of contaminants in preferred flow paths

> Natural and enhanced attenuation of large, diffuse, mixed waste contaminant plumes and sources

1. Interdependent biological, chemical, and physical processes

2. Interactions between contaminants (U, Tc, nitrate, other inorganics, and organics) and microorganisms

3. Impact of scale and heterogeneity on transport processes and predictive models $>$ Characterization, sensors, monitoring tools, and model predictions

1. Techniques for reliably monitoring and predicting the progress of long-term attenuation and remediation

2. Techniques for anticipating when remediation will or will not achieve goals

3. Testing theoretical and numerical models in the field

Information Access: Communication of research results and FRC activities has been conducted through peer review publications, newsletters, research project summaries, and maintaining and revising the FRC website and database with over 100,000 analytical data records. Over 100 peer reviewed manuscripts by PIs working at the FRC describing results of FRC field tests and laboratory tests with FRC samples have been published or are in the process of being published or reviewed. Since the year 2000 the annual FRC Workshop has been held in Oak Ridge to communicate findings from the site characterization and in situ studies and to coordinate efforts between the lead PIs for the in situ field research projects and other PIs conducting work with FRC samples. To facilitate the sharing of research findings 4 working groups (Modeling, Rates and Mechanisms, Microbial Communities, and Geochemical and Geophysical Characterization) were established that meet twice a year at the FRC Workshop and ERSP PI meeting, respectively.

Additional information, data and lists of publications can be obtained at the FRC website: (http://www.esd.ornl.gov/nabirfrc/). 